\title{
Evolution of the chloroplast genome
}

\author{
Christopher J. Howe*, Adrian C. Barbrook, V. Lila Koumandou, \\ R. Ellen R. Nisbet, Hamish A. Symington and Tom F. Wightman \\ Department of Biochemistry, University of Cambridge, Tennis Court Road, Cambridge CB2 1QW, UK
}

\begin{abstract}
We discuss the suggestion that differences in the nucleotide composition between plastid and nuclear genomes may provide a selective advantage in the transposition of genes from plastid to nucleus. We show that in the adenine, thymine (AT)-rich genome of Borrelia burgdorferi several genes have an AT-content lower than the average for the genome as a whole. However, genes whose plant homologues have moved from plastid to nucleus are no less AT-rich than genes whose plant homologues have remained in the plastid, indicating that both classes of gene are able to support a high AT-content. We describe the anomalous organization of dinoflagellate plastid genes. These are located on small circles of $2-3 \mathrm{kbp}$, in contrast to the usual plastid genome organization of a single large circle of 100-200 kbp. Most circles contain a single gene. Some circles contain two genes and some contain none. Dinoflagellate plastids have retained far fewer genes than other plastids. We discuss a similarity between the dinoflagellate minicircles and the bacterial integron system.
\end{abstract}

Keywords: nucleotide composition; transposition; dinoflagellate; plastid; integron

\section{INTRODUCTION}

It is now accepted that the first plastids arose from endosymbiosis between a photosynthetic bacterium and a nonphotosynthetic host (Howe et al. 1992). Many workers favour a monophyletic model with one primary endosymbiosis involving a single endosymbiont and a single host (see, for example, Palmer 1993). However, it has also been argued that the sequence-based trees taken to support the monophyletic model are unreliable because of the effects of systematic biases in the sequence data, and that more evidence is needed before more complex models can be ruled out (e.g. Lockhart et al. 1998). Such models might include independent acquisition of: (i) closely related endosymbionts by closely related hosts; (ii) closely related endosymbionts by distantly related hosts; (iii) distantly related endosymbionts by closely related hosts; and (iv) distantly related endosymbionts by distantly related hosts. Even if reliable sequence-based trees were available, it would be difficult to distinguish many of these models from a monophyletic origin, depending on whether the trees were based on endosymbiont or host genes, as summarized in table 1. Regardless of whether there was a single primary endosymbiosis or several, it is clear that a large fraction of the original endosymbiont genome has either been lost or transferred to the nucleus (Martin et al. 1998). Plastids typically contain of the order of 100-200 genes (Sugiura 1992; Glöckner et al. 2000), whereas the original endosymbiont, as an oxygenic photosynthetic bacterium, would probably have contained a similar number of genes to present-day cyanobacteria. For example, the

*Author for correspondence (c.j.howe@bioc.cam.ac.uk).

One contribution of 21 to a Discussion Meeting Issue 'Chloroplasts and mitochondria: functional genomics and evolution'. genome of Synechocystis sp. PCC6803 contains some 3200 genes (Nakamura et al. 1998). There has been considerable debate over the questions of why this transfer of genetic material should have occurred, and why it should have been limited to a fraction of the endosymbiont genome. It has been suggested that genes in the plastid are exposed to high levels of reactive, and potentially mutagenic, species generated during the electron transfer reactions of photosynthesis. Such reactive species would include oxygen free radicals (Allen \& Raven 1996; Race et al. 1999). It has also been suggested that movement of genes to the nucleus is beneficial in offering improved repair mechanisms, as well as placing the genes in a sexually reproducing - and therefore recombining - population (Allen \& Raven 1996; Race et al. 1999). Although the location in a sexual population should offer increased fitness through the principle known as 'Muller's ratchet', it remains to be seen if repair processes in the nucleus are inherently more effective than those in the plastid. Repair processes have been demonstrated in the chloroplast, and at least some repair activity is dependent on a homologue of the RecA protein (an important component of bacterial repair) that has been shown to be present in plastids (Cerutti et al. 1993, 1995; Cannon et al. 1995). We discuss below an additional selective advantage proposed for the movement of genes to the nucleus (Howe et al. 2000).

If there are advantages in moving genes from the plastid to the nucleus, there is then the question of why not all genes have been transposed. It is likely that the gene for tRNA-Glu is needed for activation of glutamate in tetrapyrrole biosynthesis (Howe \& Smith 1991). However, given that the tRNA-Glu could be transcribed by a nucleus-encoded plastid polymerase, this would not require the retention of protein genes in the plastid. Two main suggestions have been advanced to explain this. The first is that certain plastid proteins may be inherently diffi- 
Table 1. Likely origins of plastids inferred under monophyly or different models of polyphyly.

\begin{tabular}{lccc}
\hline symbionts & hosts & host gene trees & symbiont gene trees \\
\hline $\begin{array}{l}\text { monophyletic } \\
\text { unique } \\
\text { polyphyletic } \\
\text { closely related } \\
\text { closely related } \\
\text { distantly related } \\
\text { distantly related }\end{array}$ & unique & monophyletic & monophyletic \\
\hline
\end{tabular}

cult to transport across the plastid envelope. It would therefore be difficult to relocate the genes for such proteins to the nucleus, with consequent synthesis of the proteins in the cytosol and post-translational import into the organelle. However, several studies have shown that individual plastid genes can be artificially introduced into the nucleus and, if the genes have been modified by the fusion of a region encoding a plastid-targeting sequence to the coding sequence for the mature protein, the resulting protein can be re-imported effectively into the organelle (Cheung et al. 1988; Kanevski \& Maliga 1994). Although such studies show that these proteins can, in principle, be re-imported into the organelle, they do not exclude the possibility that the need for import may cause a minor reduction in fitness on the organism. A second suggestion for the retention of genes by the plastid is that it allows a rapid regulation of expression in response to the redox state of the organelle (Allen 1993; Pfannschmidt et al. 1999). We will discuss the much-reduced dinoflagellate plastid genome, and argue that its residual gene content is consistent with Allen's proposal.

\section{TRANSPOSITION OF GENES TO THE NUCLEUS}

One of the notable features of plastid genomes is their high AT-content, both in coding regions and in noncoding regions. The high AT-content is not restricted to green plastids; rather it is seen across the whole spectrum of pigment types, and is higher than generally seen in cyanobacteria. For example, the plastid genomes of Nicotiana tabacum, Porphyra purpurea and Odontella sinensis are ca. $62 \%, 67 \%$ and $68 \%$ AT, respectively (Reith \& Munholland 1995; Kowallik et al. 1995). The genome of Synechocystis sp. PCC6803 is ca. 52\% AT (Nakamura et al. 1998). Although one cannot exclude the possibility that the plastid originated from a bacterial species with a more AT-rich genome, it seems more likely that the plastid genome has become AT-rich since endosymbiosis. This shift in nucleotide composition could be due to the nature of DNA damage occurring in the plastid, or to a tendency of the plastid DNA polymerase to mis-incorporate A and $T$ rather than $G$ and $C$ in replication, or to a bias in the DNA repair machinery. (Interestingly, mitochondrial genomes are also rather AT-rich (Lang et al. 1999).) It is worth noting that such a bias in nucleotide composition causes serious problems for phylogenetic inference based on plastid genes. Many of the techniques used assume that nucleotide composition remains constant over time, and violation of this can result in organisms with similar nucleotide compositions being grouped artefactually closely, with implications for attempts to discriminate between monophyly and polyphyly of plastid origins (Lockhart et al. 1992). Notwithstanding the degeneracy of the genetic code, the biased nucleotide composition affects the amino-acid composition of the proteins encoded. This can be seen particularly clearly by looking at proteins that are plastid encoded in some species, and nuclear encoded in others. A good example is the plastid SecA, which is involved in translocation of lumenal proteins across the thylakoid membrane. SecA is encoded in the nucleus of green plants and algae, and in the plastid of non-green algae. Table 2 shows the predicted content of several amino acids for SecA proteins from different sources (Barbrook et al. 1998). The codons for the amino acids alanine, glycine and proline are GC-rich, in that they have necessarily to contain at least two $\mathrm{G}$ or $\mathrm{C}$ residues (and may contain three), and the codons for phenylalanine, isoleucine, lysine, asparagine and tyrosine are AT-rich, in that they have necessarily to contain at least two A or $\mathrm{T}$ residues (and may contain three). The SecA protein from the red and brown algae can be seen to be relatively depleted in the GC-rich codons for $(A, G, P)$ and enriched in the AT-rich codons $(\mathrm{F}, \mathrm{I}, \mathrm{K}, \mathrm{N}, \mathrm{Y})$. Thus, if a protein remains encoded in the plastid, there will be a shift in its amino-acid composition. For many proteins, this may be detrimental to their function, and there may therefore be a selective advantage in transfer of the gene to the nucleus. Genes that have moved to the nucleus have been described as 'molecular refugees' moving to a less oppressive coding environment (Howe et al. 2000). This potential driving force for the transfer of genes to the nucleus may not act independently of the other driving forces proposed, such as Muller's ratchet, but it may act synergistically with them. (Although this argument has been presented in terms of a relatively GC-rich organelle genome becoming AT-rich, if the plastid originated from an AT-rich bacterium and genes have the possibility of becoming more GC-rich by transposition to the nucleus, the same argument applies.)

If some proteins were particularly seriously affected by the shift in amino-acid composition resulting from an increased AT-content of their genes, there might be a greater advantage in the transfer of those genes to the nucleus. (Conversely, the shift towards AT-richness might even be advantageous for some genes and proteins, making it less favourable for the genes to be transposed to the nucleus.) Differing effects of a shift in amino-acid composition on different proteins might therefore offer an explanation of why some genes have been retained by the plastid, some have been transferred to the nucleus, and 
Table 2. Content (\%) of GC-rich (A,G,P) and GC-poor (F,I,K,N,Y) codons of the secA gene from green plants (Pisum sativum, Spinacia oleracea), oxygenic photosynthetic bacteria (Anacystis nidulans R2, Anabaena variabilis, Phormidium laminosum, Synechocystis sp. PCC6803, Prochloron didemni, Prochlorothrix hollandica) and plastid genomes of algae (Antithamnion sp., Porphyra purpurea, Heterosigma carterae, Odontella sinensis and Pavlova lutherii).

(Averages shown in italics for a group of organisms are above the overall average. Those underlined are below the overall average. Modified from Barbrook et al. (1998).)

\begin{tabular}{|c|c|c|c|c|c|c|c|c|}
\hline & \multicolumn{3}{|c|}{ GC-rich } & \multicolumn{5}{|c|}{ GC-poor } \\
\hline & $\stackrel{\mathrm{A}}{\mathrm{GCN}}$ & $\underset{\mathrm{GGN}}{\mathrm{G}}$ & $\begin{array}{c}\mathrm{P} \\
\mathrm{CCN}\end{array}$ & $\begin{array}{c}\mathrm{F} \\
\mathrm{TTT} / \mathrm{C}\end{array}$ & $\begin{array}{c}\mathrm{I} \\
\mathrm{ATA} / \mathrm{T} / \mathrm{C}\end{array}$ & $\begin{array}{c}\mathrm{K} \\
\mathrm{AAA} / \mathrm{G}\end{array}$ & $\begin{array}{c}\mathrm{N} \\
\mathrm{AAT} / \mathrm{C}\end{array}$ & $\begin{array}{c}\mathrm{Y} \\
\mathrm{TAT} / \mathrm{C}\end{array}$ \\
\hline \multicolumn{9}{|l|}{ nuclear or bacterial } \\
\hline Pisum sativum & 5.0 & 4.0 & 2.0 & 4.0 & 7.9 & 7.9 & 3.0 & 0.0 \\
\hline Spinacia oleracea & 5.9 & 3.0 & 2.0 & 4.0 & 8.9 & 7.9 & 4.0 & 0.0 \\
\hline Anacystis nidulans $\mathrm{R} 2$ & 6.9 & 5.9 & 3.0 & 3.0 & 5.9 & 5.9 & 4.0 & 2.0 \\
\hline Anabaena variabilis & 6.9 & 4.0 & 2.0 & 2.0 & 8.9 & 5.9 & 3.0 & 2.0 \\
\hline Phormidium laminosum & 5.9 & 1.0 & 3.0 & 2.0 & 5.0 & 5.9 & 5.9 & 3.0 \\
\hline Synechocystis sp. & 4.0 & 2.0 & 2.0 & 2.0 & 6.9 & 6.9 & 5.9 & 2.0 \\
\hline Prochloron didemni & 6.9 & 0.0 & 3.0 & 2.0 & 4.0 & 6.9 & 5.9 & 3.0 \\
\hline Prochlorothrix hollandica & 5.9 & 2.0 & 4.0 & 2.0 & 6.9 & 5.0 & 4.0 & 3.0 \\
\hline average & 5.9 & 2.7 & 2.6 & $\underline{2.6}$ & $\underline{6.8}$ & $\underline{6.5}$ & $\underline{4.2}$ & $\underline{1.9}$ \\
\hline \multicolumn{9}{|l|}{ organellar } \\
\hline Antithamnion sp. & 4.0 & 0.0 & 0.0 & 1.0 & 13.9 & 15.8 & 10.9 & 5.0 \\
\hline Porphyra purpurea & 4.0 & 0.0 & 2.0 & 2.0 & 11.9 & 7.9 & 5.0 & 5.9 \\
\hline Heterosigma carterae & 7.9 & 0.0 & 2.0 & 7.9 & 13.9 & 12.9 & 7.9 & 4.0 \\
\hline Odontella sinensis & 5.0 & 0.0 & 4.0 & 4.0 & 11.9 & 6.9 & 7.9 & 3.0 \\
\hline Pavlova lutherii & 3.0 & 2.0 & 0.0 & 4.0 & 10.9 & 12.9 & 7.9 & 5.9 \\
\hline average & $\underline{4.8}$ & $\underline{0.4}$ & $\underline{1.6}$ & 3.8 & 12.5 & 11.3 & 7.9 & 4.8 \\
\hline average overall & $\overline{5.5}$ & $\overline{1.8}$ & $\overline{2.2}$ & 3.0 & 9.0 & 8.4 & 5.6 & 3.0 \\
\hline
\end{tabular}

others have different locations in different species. If individual genes were affected in different ways by the shift in nucleotide composition, this might become apparent by looking at homologues in bacterial genomes with biased nucleotide compositions. In an AT-rich bacterial genome, genes whose products were adversely affected by the high AT-content (under the 'molecular refugees' hypothesis, homologues of nuclear genes for plastid proteins) might be expected to have adopted a lower AT-content than genes whose products were able to tolerate a high AT-content (i.e. homologues of plastid genes for plastid proteins). We have tested this using the genome of the bacterium Borrelia burgdorferi and a set of genes for polypeptides of the ribosome and of the ATP synthase complex (figure 1). The overall AT-content of the genome is high (ca. 71\%), and the test set of genes had a lower AT-content than this (ca. 68\%). The lower AT-content of the genes was more marked when the first and second codon positions only were considered $(63 \%)$. However, when the test genes were divided into groups according to whether the plastid homologue was plastid or nuclear encoded, no clear pattern was seen. Indeed, the B. burgdorferi genes with plastidencoded plastid homologues seemed to be slightly more GC-rich than those with nuclear-encoded plastid homologues.

It therefore seems that in an AT-rich genome, genes will maintain a lower AT-content than the genome as a whole, and there may well be an advantage in movement of genes to a less AT-rich genome. There is no evidence that genes whose homologues have moved to the nucleus in plants and algae have a lower AT-content in B. burgdorferi than genes whose homologues have remained in the plastid. This indicates that although the shift in AT-content may

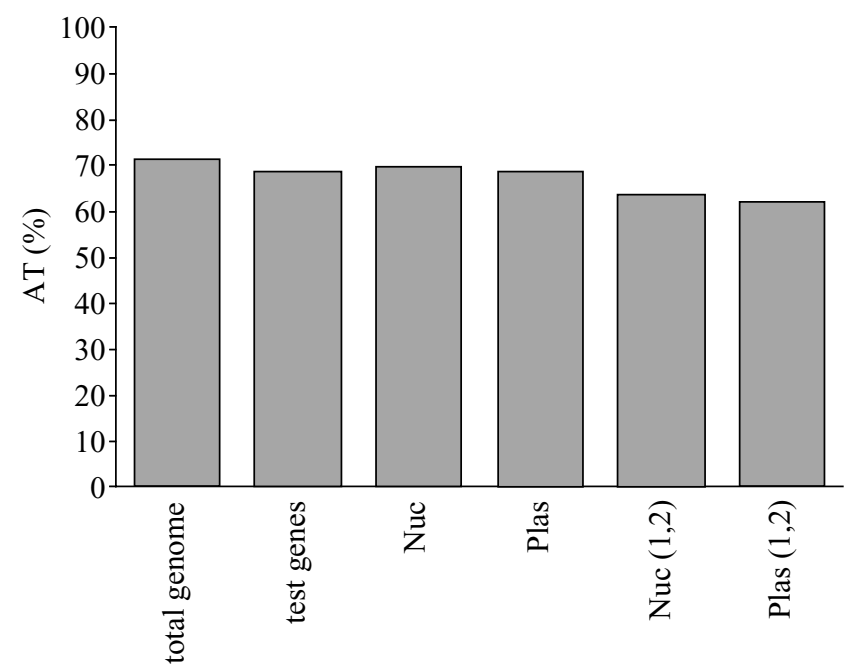

Figure 1. AT content of genes in Borrelia burgdorferi. The figure shows the AT content of the complete genome (total genomes) and a subset (test genes) of the coding regions for ribosomal proteins and subunits of ATP synthase, whose plant homologues are either encoded in the nucleus in land plants generally $(r p s 1,5,6,9,10,13,17,20,21$ rpl1,3-5,9$13,15,17,25,27-31,34, a t p C, D)$ or in the plastid (rps2$4,7,8,11,12,14,18,19$ rpl14,16,20,22,23,33 atp $A, B, E)$. The AT-contents of the former and latter sets separately are shown for the complete coding regions (Nuc and Plas, respectively) and for the 1 st and 2 nd codon positions alone $\operatorname{Nuc}(1,2)$ and $\operatorname{Plas}(1,2))$.

provide a driving force for movement of genes generally to the nucleus, it may not be able to account for which genes are transferred. (However, it remains possible that 
individual positions within the proteins encoded may be particularly affected, and that this was masked in the analysis of $B$. burgdorferi sequences by considering the coding region as a whole. Recognizing this would require the identification of residues that are generally conserved and seeing to what extent these have resisted the effects of biased nucleotide composition in genomes such as $B$. burgdorferi.) It is possible that considerations such as the need for redox control may be responsible for determining which genes are retained in the organelle.

\section{A REDUCED PLASTID GENOME IN DINOFLAGELLATES}

The general pattern of plastid genome organization is for the complement of 100-200 genes to be located on a large circular molecule (e.g. Sugiura 1992; Glöckner et al. 2000). However, a striking exception to this has been shown in several species of peridinin-containing dinoflagellate algae. The organization of plastid genes has been best characterized in Heterocapsa triquetra, Amphidinium operculatum and $A$. carterae (Zhang et al. 1999; Barbrook \& Howe 2000; Barbrook et al. 2001; Hiller 2001). These species appear to lack a conventional plastid genome and have instead several small circular DNA molecules, typically about $2-3 \mathrm{kbp}$ in size, which generally contain a single gene. Although plasmid-like DNAs have been reported from plastids of some green algae, they seem to be in addition to the 'main' chloroplast genome and may not encode functional genes (e.g. La Claire \& Wang 2000). The difficulty of isolating intact dinoflagellate plastids means that these minicircles have not yet been shown directly to be located in the plastid. However, the indirect evidence for this location appears strong. The minicircle genes encode products that, in all other species, are plastid-encoded, and these include rRNA (see below). Furthermore, the predicted protein products do not include organellar targeting sequences, and no other copies of the minicircle genes have been detected.

Remarkably, only few genes have been identified so far on the putative plastid minicircles. The following have been reported on minicircles from one or more species: $a t p A, a t p B, p e t B, p e t D, p s a A, p s a B, p s b A, p s b B, p s b C, p s b D$, $p s b E, 16 \mathrm{~S}$ rRNA and 23S rRNA (Zhang et al. 1999; Barbrook \& Howe 2000; Barbrook et al. 2001; Hiller 2001). It is remarkable that no evidence has yet been found of RNA polymerase subunit genes, ribosomal protein genes or tRNA genes. As discussed above, one proposal for the retention of a plastid genome is to allow rapid regulation of important genes in response to redox processes in the plastid (Pfannschmidt et al. 1999). The fact that all the protein genes identified so far encode major subunits of the complexes of the light reactions of oxygenic photosynthesis seems to be consistent with this. Several features of the dinoflagellate plastid minicircles are worthy of comment.

(i) Minicircles contain a conserved 'core' region. This region is similar between minicircles of a given species carrying different genes. There are sections within the core that are essentially completely conserved across all minicircles of a given species, and others that are moderately well conserved: in many cases across some of the minicircles of a species but not all of them. The sequences of core regions of closely related species are very different from each other. Strikingly, the coding regions of minicircles with different genes are always in the same orientation with respect to the core region. Given the number of minicircles that have now been studied, it seems unlikely that this conservation of orientation is by chance. We return to this observation later.

(ii) Some minicircles contain more than one gene. For example, the $p e t B$ and $a t p A$ genes are on a single minicircle in both $A$. carterae and $A$. operculatum (Barbrook et al. 2001; Hiller 2001). The same is true for $p s b D$ and $p s b E$ (Hiller 2001; R. E. R. Nisbet, unpublished data). These arrangements are not seen across all species. For example, the $p e t B$ and atp $A$ genes of $H$. triquetra are on different minicircles (Zhang et al. 1999). The arrangements also do not reflect the general pattern in conventional plastid genomes, where $p e t B, a t p A, p s b D$ and $p s b E$ genes are located at different positions, so it is unlikely that these two-gene minicircles can have been derived simply by fragmentation of a conventional genomic circle. Northern analysis of RNA from $A$. operculatum indicates that the $\operatorname{atp} A$ and $\operatorname{pet} B$ genes are either not co-transcribed or form part of an unstable dicistronic transcript that is very rapidly cleaved into monocistronic ones (Barbrook et al. 2001).

(iii) Some minicrcles contain gene fragments, or no genes at all. Several minicircles have been reported from $A$. operculatum and $A$. carterae that contain fragments of coding regions, or no identifiable coding regions at all, although they retain a recognizable minicircle core (Barbrook et al. 2001; Hiller 2001; V. L. Koumandou and R. E. R. Nisbet, unpublished data). More complex minicrcles have been reported from $H$. triquetra that contain fragments of more than one gene, and it has been proposed that these originated by fusion of two separate minicircles followed by deletion (Zhang et al. 2001).

(iv) The coding regions of the minicircles show unusual features. One of the most striking features revealed by inspection of the coding regions is the apparent use of anomalous initiation codons. For example, GTA has been proposed as an initiation codon for the $p s a A$ and $p s b B$ genes, and possibly also $p s b C$ of A. operculatum (Barbrook \& Howe 2000; Barbrook et al. 2001). In the case of $p s b B$, the predicted $\mathrm{N}$ terminus of the protein aligns closely with well-conserved sequences from other plastids (figure 2). This makes the assignment of GTA as initiation codon reasonably convincing, although there are as yet no direct protein sequence data to confirm it. A limited number of studies using RT-PCR have so far failed to detect editing of dinoflagellate plastid transcripts, although the possible existence either of a low level of edited transcripts or of heavily modified transcripts (which therefore escaped amplification in RT-PCR) cannot be excluded. If GTA is indeed used as an initiation codon, this would be very unusual for organelle genomes generally (Edqvist et al. 2000). 
Amphidinium operculatum Heterocapsa triquetra

Guillardia theta

odontella sinenis

Cyanidium caldarium

Anabaena sp.

Chlamydomonas reinhardtii

Marchantia polymorpha

Euglena gracilis
VRLPWFRVHIVVLNDPGRLISVHLMHTGLISGWAGLMALYELIVTDP MRLPWFRVHIVILNDPGRLISVHIMHTALVAGWAAVMTLYELI ILDP MGLPWYRVHTVVLNDPGRLIAVHLMHTALVAGWAGSMALYELAVFDP MALPWYRVHTVVLNDPGRLIAVHLMHTALVAGWAGSMALYELAVFDP MALPWYRVHTVVLNDPGRLISVHLMHTALVSGWAGSMALYELAVFDP MGLPWYRVHTVVLNDPGRLISVHLMHTALVAGWAGSMALYELAIYDP MGLPWYRVHTVVINDPGRLISVHLMHTALVSGWAGSMALFEISVFDP MGLPWYRVHTVVLNDPGRLIAVHLMHTALVSGWAGSMALYELAVFDP MGLPWYRVHTVVLNDPGRF ISVHLMHTALVSGWAGSMALYELAIFDP

Figure 2. Aligned predicted N-termini of $p s b B$ from a range of plants and algae.

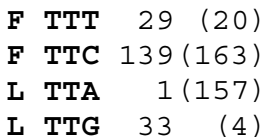

I TTG $33 \quad(4)$

L CTT $122 \quad(87)$

L CTC 75 (56)

L CTA 45 (1)

I CTG $19 \quad(0)$

$\begin{array}{lrrr}\text { S } & \text { TCT } & 117 & (70) \\ \text { S } & \text { TCC } & 75 & (2) \\ \text { S } & \text { TCA } & 7(130) \\ \text { S } & \text { TCG } & 37 & (1)\end{array}$

P CCT

P $\mathrm{CCC}$

P CCA

P CCG

$\begin{array}{rr}43 & (44) \\ 1 & (0) \\ 37 & (51) \\ 17 & (5)\end{array}$

T ACT

T ACC

T ACA

T ACG

$\begin{array}{rr}45 & (76) \\ 43 & (0) \\ 52 & (47) \\ 5 & (0)\end{array}$

A GCT

A $\mathrm{GCC}$

A GCA

A GCG

\begin{tabular}{|c|c|c|c|c|c|}
\hline V GTT & 60 & 109) & A & GCT & 73 \\
\hline V GTC & 51 & (76) & A & GCC & 26 \\
\hline GTA & 56 & (9) & A & GCA & 81 \\
\hline GTG & 50 & (3) & A & GCG & 62 \\
\hline
\end{tabular}

$\begin{array}{rrrr}\text { Y TAT } & 60 & (76) \\ \text { Y TAC } & 45 & (31) \\ \text { * TAA } & 2 & (5) \\ \text { * TAG } & 4 & (1)\end{array}$

H CAT 47 (62)

H CAC 32 (19)

Q CAA 22 (50)

Q CAG 58 (27)

$\begin{array}{llrr}\text { C } & \text { TGT } & 10 & (16) \\ \text { C } & \text { TGC } & 12 & (6) \\ \text { * } & \text { TGA } & 0 & (0) \\ \text { W } & \text { TGG } & 65 & (75)\end{array}$

$\begin{array}{llll}\text { R CGT } & 57 \text { (60) }\end{array}$

$\begin{array}{lll}R & \text { CGC } & 3\end{array}$

$\begin{array}{lll}\text { R CGA } 7 \text { (1) } & 7 \text { ( }\end{array}$

R CGG 0 (0)

$\begin{array}{llrr}\text { N } & \text { AAT } & 34 & (26) \\ \text { N } & \text { AAC } & 50 & (54) \\ \text { K } & \text { AAA } & 1 & (4) \\ \text { K } & \text { AAG } & 55 & (61) \\ & & & \\ & & & \\ \text { D } & \text { GAT } & 57 & (77) \\ \text { D } & \text { GAC } & 25 & (14) \\ \text { E } & \text { GAA } & 18 & (66) \\ \text { E } & \text { GAG } & 62 & (25)\end{array}$

$\begin{array}{llrr}\text { S } & \text { AGT } & 15 & (29) \\ \text { S } & \text { AGC } & 6 & (15) \\ \text { R } & \text { AGA } & 0 & (49) \\ \text { R } & \text { AGG } & 32 & (1)\end{array}$

G GGT 192 (259)

G GGC 26 (13)

G GGA 17 (4)

G GGG 2 (1)

Figure 3. Codon preferences for the $p s a A, p s b A, B, C, a t p A$ and $p e t B$ genes of $A m p h i d i n i u m$ operculatum and (in parentheses) Heterocapsa triquetra.

Figure 3 shows the codon preference for $A$. operculatum and $H$. triquetra over a set of genes, $p s a A, p s b A, p s b B, p s b C$, pet $B$ and $a t p A$, which have been characterized from both. The codon preference is heavily biased, although there does not appear to be a consistent pattern, such as a preference for $\mathrm{A}$ or $\mathrm{T}$ at the third codon position. So, for example, there is a strong preference in $A$. operculatum for GGT (Gly) over GGC/A/G and TCT (Ser) over TCC/A/G or AGT/C, yet TTC (Phe) is much preferred over TTT. There are also clear differences in the bias between the species. For example, although $H$. triquetra has the same preference for TTC and GGT, TCA (which was only rarely used in $A$. operculatum) is much preferred as a serine codon. This pattern of codon preferences is rather different from that seen in other plastids, where there is a consistent preference for $\mathrm{A}$ or $\mathrm{T}$ at the third codon position. The pattern of dinoflagellate preferences is arguably rather more similar to cyanobacteria, where the preferred nucleotide at the third position differs among different codon families (compare, for example TTT/C with $\mathrm{GGT} / \mathrm{C} / \mathrm{A} / \mathrm{G}$ ) as shown in figure 4 . It will be interesting to see how patterns of codon preference vary across a broader range of dinoflagellates. If any are found to have a 'conventional' plastid genome organization, it will be particularly interesting to see if they also have the conventional plastid preference for third position A or $\mathrm{T}$.

Why should the dinoflagellate plastid genome be organized in this way? The limited number of genes ident- ified makes it tempting to suggest that this represents a plastid genome in the final stages of gene transfer to the nucleus, with only those genes left that are essential for effective regulation in response to redox or other requirements. It is of course possible that additional genes will be discovered. However, the results of PCR with primers for genes that are generally located in the chloroplast, together with sequencing of randomly selected clones indicates that the number of additional genes found will be low. In support of this, the gene for the large subunit of ribulose bis-phosphate carboxylase has been shown to be located in the nucleus in the dinoflagellate Gonyaulax polyedra (although the gene encodes a different form of the enzyme from that usually found in plastids (Morse et al. 1995)). The ribulose bisphosphate carboxylaseoxygenase large subunit gene is plastid located in other algae and plants. Why the dinoflagellates should be in such an advanced state of gene loss is not clear. It is also not clear how the minicircles are generated. They have a superficial resemblance to the small circular DNA species found in plant mitochondria, which are derived by fragmentation of a 'master' chromosome by recombination across repeated sequences (Lonsdale et al. 1984). However, there is as yet no evidence of a master chromosome in dinoflagellate plastids. In addition, in the rare examples where there are two genes on the same minicircle, these genes are not generally adjacent in other plastid genomes, 


$\begin{array}{lrrr}\text { F } & \text { TTT } & 154 & (80) \\ \text { F } & \text { TTC } & 29 & (102) \\ \text { L } & \text { TTA } & 186 & (35) \\ \text { L } & \text { TTG } & 21 & (91) \\ & & & \\ \text { L CTT } & 67 & (23) \\ \text { L } & \text { CTC } & 1 & (53) \\ \text { L } & \text { CTA } & 10 & (15) \\ \text { L } & \text { CTG } & 1 & (59) \\ & & & \\ & & & \\ \text { I } & \text { ATT } & 146 & (99) \\ \text { I } & \text { ATC } & 25 & (87) \\ \text { I } & \text { ATA } & 30 & (1) \\ \text { M } & \text { ATG } & 64 & (81) \\ & & & \\ & & & \\ \text { V } & \text { GTT } & 111 & (54) \\ \text { V } & \text { GTC } & 3 & (40) \\ \text { V } & \text { GTA } & 80 & (45) \\ \text { V } & \text { GTG } & 7 & (59)\end{array}$

$\begin{array}{llrr}\text { S } & \text { TCT } & 78 & (33) \\ \text { S } & \text { TCC } & 7 & (74) \\ \text { S } & \text { TCA } & 24 & (5) \\ \text { S } & \text { TCG } & 5 & (6)\end{array}$

P CCT

$\mathrm{P} \mathrm{CCC}$

P CCA

P CCG

$\begin{array}{rrrr}\text { T } & \text { ACT } & 92 & (36) \\ \text { T } & \text { ACC } & 10 & (99) \\ \text { T ACA } & 47 & (4) \\ \text { T } & \text { ACG } & 3 & (18)\end{array}$

A GCT 170 (89)

A GCC $6(144)$

A GCA 78 (8)

A GCG 5 (23)

$\begin{array}{rrrr}\text { Y TAT } & 61 & (34) \\ \text { Y TAC } & 29 & (51) \\ \text { * TAA } & 6 & (2) \\ \text { * TAG } & 0 & (4)\end{array}$

C TGT

$8(14)$

$4 \quad(4)$

* TGA 0 (0)

W TGG 78 (79)
H CAT 76 (21)

H CAC 11 (68)

Q CAA 92 (61)

Q CAG 7 (37) $\begin{array}{llll}\text { R CGT } & 60 & \text { (37) }\end{array}$

R CGC 9 (23)

$\begin{array}{llll}\text { R CGA } 10 \text { (3) } & 10\end{array}$

R CGG 1 (41)

$\begin{array}{lllllrr}\text { N AAT } & 63 & (36) & \text { S AGT } & 49 & (27) \\ \text { N } & \text { AAC } & 24 & (58) & \text { S AGC } & 12 & (35) \\ \text { K AAA } & 72 & (58) & \text { R AGA } & 32 & (3) \\ \text { K AAG } & 12 & (22) & \text { R AGG } & 4 & (2)\end{array}$

Figure 4. Codon preferences for the $p s a A, p s b A, B, C, a t p A$ and $p e t B$ genes in the plastid of the liverwort Marchantia polymorpha and (in parentheses) the cyanobacterium Synechocystis sp. PCC6803.
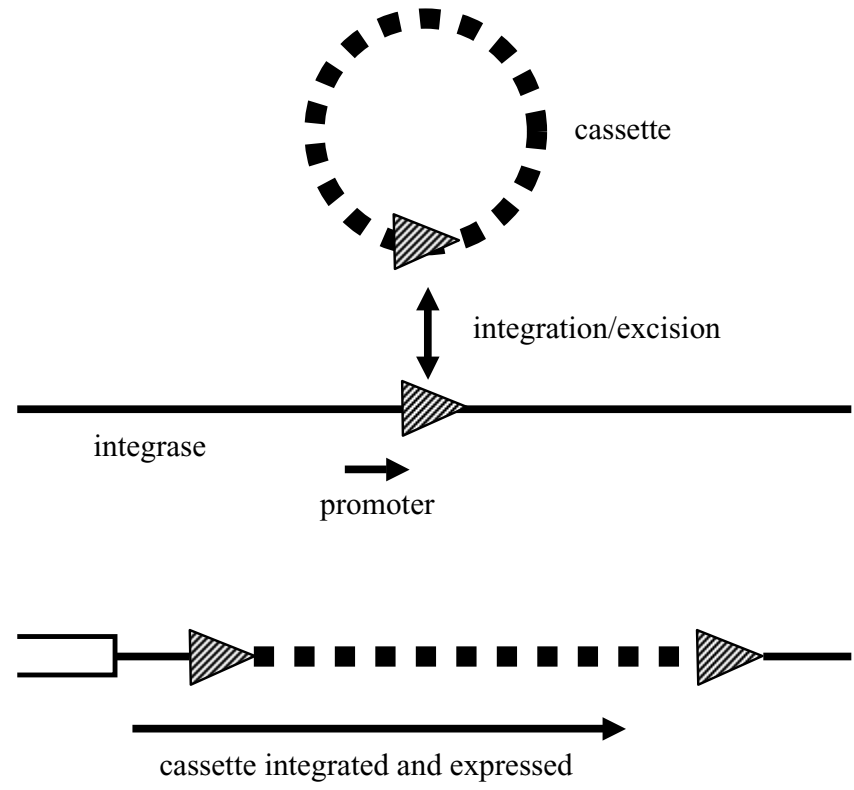

Figure 5. Insertion and expression of a bacterial integron cassette.

indicating that the two-gene minicircles are not generated by simple fragmentation of a larger minicircle.

The minicircles demonstrate an intriguing similarity to the cassettes of bacterial integrons. The latter are naturally occurring gene capture systems, in which circular molecules carrying an open reading frame and a conserved $59 \mathrm{bp}$ core region are inserted into the bacterial chromosome by recombination across a similar sequence in the bacterial chromosome. This integration is carried out by an integrase (IntI) encoded adjacent to the integration site. The integration places the open reading frame under the control of a promoter also present at the insertion site (RoweMagnus \& Mazel 1999, 2001). This results in the expression of the open reading frame in the incoming cassette (figure 5). These systems are widely used by bacteria, especially as a way of acquiring and exchanging antibiotic resistance. Several cassettes can integrate at a given site, to generate a 'super-integron'. Because expression of the cassette gene relies on integration placing it under the control of the promoter at the insertion site, the open reading frame of any cassette is always in the same orientation with regard to the $59 \mathrm{bp}$ core region. This resembles the situation in dinoflagellate plastid minicircles, where the coding region is always in the same orientation with regard to the core sequence. The $59 \mathrm{bp}$ core elements of integrons are flanked by imperfect inverted repeats (Hall et al. 1991), and it is interesting that the core regions of dinoflagellate minicircles also generally contain imperfect inverted repeats (Barbrook et al. 2001; Zhang et al. 2002). At least in the case of the core region of $A$. operculatum, the inverted repeats and the region between them is remarkably similar in size $(55 \mathrm{bp})$ to the $59 \mathrm{bp}$ of the integron core region (Barbrook et al. 2001). Although some of the inverted repeats in dinoflagellate core regions are larger than this, the same is true for the cores of integron cassettes (Recchia \& Hall 1997). Once inserted, integron cassettes can be re-excised by a reversal of the insertion event. How cassettes are generated initially is not clear. It has been proposed that they may be produced by reverse transcription of mRNA species. This would account for the absence of a promoter. Given the high error rate of reverse transcriptase, it is interesting to note that the dinoflagellate minicircle genes are highly diverged from their homologues in other plastids (Zhang et al. 2000), which might be expected if they were generated by an error-prone mechanism. One possibility for the origin of the $59 \mathrm{bp}$ element of bacterial integrons is that it derives from stem-loops at the end of the transcripts (i.e. from a bacterial transcription terminator). Transcripts in plastids of green plants and algae typically end with stem-loops, although they are generally processing sites rather than transcription terminators (Stern et al. 1991). An alternative proposal for the origin of the $59 \mathrm{bp}$ element of bacterial integrons is that it is a separate element added either to the RNA or the cDNA after reverse transcription (Recchia \& Hall 1997). 
There are therefore many interesting similarities between the dinoflagellate minicircles and bacterial integron systems. Maybe in the same way that integrons are used for lateral transfer of coding regions between different genomes, the minicircles are part of a system for transfer of coding regions between different genomes within the same cell, i.e. for moving genes from the chloroplast to the nucleus. On this basis, one might expect to find integrated copies of minicrcles in the nuclear genome, perhaps in association with the integrase gene. It may be that the minicircles remaining in the plastid are ones that have failed to be incorporated into the nucleus, because their continued presence in the plastid is required for efficient regulation (Pfannschmidt et al. 1999). These minicircles may have acquired replication origins to facilitate their continued propagation in the plastid.

There are several important questions remaining to be answered. Perhaps the most significant is whether the minicircles are indeed located in the plastid, or whether they are actually nuclear (in addition or instead). Do all dinoflagellates have this anomalous gene organization, and is there also a 'master' circle that has not yet been found? How many additional genes are located on minicircles, and where are the tRNA genes? How significant is the resemblance to bacterial integrons? Are there integrated copies of the minicircles, and if so, in which compartments? How are the minicircles replicated, and how are the genes they contain transcribed? Is there any editing of transcripts, or is the primary amino-acid sequence of plastid proteins the same as that predicted from the open reading frames in the minicircles? How are the minicircles with only fragments of genes, or no genes at all, generated, and do they have a function?

We thank BBSRC, The Broodbank Trust, Corpus Christi College and the Cambridge European Trust for financial support.

\section{REFERENCES}

Allen, J. F. 1993 Control of gene expression by redox potential and the requirement for chloroplast and mitochondrial genomes. F. Theor. Biol. 165, 609-631.

Allen, J. F. \& Raven, J. A. 1996 Free-radical-induced mutation vs redox regulation: costs and benefits of genes in organelles. 7. Mol. Evol. 42, 482-492.

Barbrook, A. C. \& Howe, C. J. 2000 Minicircular plastid DNA in the dinoflagellate Amphidinium operculatum. Mol. Gen. Genet. 263, 152-158.

Barbrook, A. C., Lockhart, P. J. \& Howe, C. J. 1998 Phylogenetic analysis of plastid origins based on $\sec A$ sequences. Curr. Genet. 34, 336-341.

Barbrook, A. C., Symington, H., Nisbet, R. E. R., Larkum, A. \& Howe, C. J. 2001 Organisation and expression of the plastid genome of the dinoflagellate Amphidinium operculatum. Mol. Genet. Genomics 266, 632-638.

Cannon, G. C., Hedrick, L. A. \& Heinhorst, S. 1995 Repair mechanisms of UV-induced DNA damage in soybean chloroplasts. Plant Mol. Biol. 29, 1267-1277.

Cerutti, H., Ibrahim, H. Z. \& Jagendorf, A. T. 1993 Treatment of pea (Pisum sativum L.) protoplasts with DNA-damaging agents induces a 39-kilodalton chloroplast protein immunologically related to Escherichia coli RecA. Plant Physiol. 102, 155-163.

Cerutti, H., Johnson, A. M., Boynton, J. E. \& Gillham, N. W. 1995 Inhibition of chloroplast DNA recombination and repair by dominant negative mutants of Escherichia coli RecA. Mol. Cell. Biol. 15, 3003-3011.

Cheung, A. Y., Bogorad, L., Van Montagu, M. \& Schell, J. 1988 Relocating a gene for herbicide tolerance: a chloroplast gene is converted into a nuclear gene. Proc. Natl Acad. Sci. USA 85, 391-395.

Edqvist, J., Burger, G. \& Gray, M. W. 2000 Expression of mitochondrial protein-coding genes in Tetrahymena pyriformis. F. Mol. Biol. 297, 381-393.

Glöckner, G., Rosenthal, A. \& Valentin, K. 2000 The structure and gene repertoire of an ancient red algal plastid genome. F. Mol. Evol. 51, 382-390.

Hall, R. M., Brookes, D. E. \& Stokes, H. W. 1991 Site-specific insertion of genes into integrons: role of the 59-base element and determination of the recombination cross-over point. Mol. Microbiol. 5, 1941-1959.

Hiller, R. G. 2001 'Empty' minicrcles and petB/atpA and $\mathrm{psbD} / \mathrm{psbE}\left(\mathrm{cyt}_{559} \alpha\right)$ genes in tandem in Amphidinium carterae plastid DNA. FEBS Lett. 505, 449-452.

Howe, C. J. \& Smith, A. G. 1991 Plants without chlorophyll. Nature 349, 109.

Howe, C. J., Beanland, T. J., Larkum, A. W. D. \& Lockhart, P. J. 1992 Plastid origins. Trends Ecol. Evol. 7, 378-383.

Howe, C. J., Barbrook, A. C. \& Lockhart, P. J. 2000 Organelle genes: do they jump or are they pushed? Trends Genet. 16, 65-66.

Kanevski, I. \& Maliga, P. 1994 Relocation of the plastid $r b c L$ gene to the nucleus yields functional ribulose-1,5-bis-phosphate carboxylase in tobacco chloroplasts. Proc. Natl Acad. Sci. USA 91, 1969-1973.

Kowallik, K. V., Stoebe, B., Schaffran, I., Kroth-Pancic, P. \& Freier, U. 1995 The chloroplast genome of a chlorophyll a + c-containing alga, Odontella sinensis. Plant Mol. Biol. Rep. 13, 336-342.

La Claire, J. W. \& Wang, J. 2000 Localization of plasmid-like DNA in giant-celled marine algae. Protoplasma 213, 157164.

Lang, B. F., Gray, M. W. \& Burger, G. 1999 Mitochondrial genome evolution and the origin of eukaryotes. A. Rev. Genet. 33, 351-397.

Lockhart, P. J., Howe, C. J., Bryant, D. A., Beanland, T. J. \& Larkum, A. W. D. 1992 Substitutional bias confounds inference of cyanelle origins from sequence data. F. Mol. Evol. 34, 153-162.

Lockhart, P. J., Steel, M. A., Barbrook, A. C., Huson, D. H., Charleston, M. A. \& Howe, C. J. 1998 A covariotide model explains apparent phylogenetic structure of oxygenic photosynthetic lineages. Mol. Biol. Evol. 15, 1183-1188.

Lonsdale, D. M., Hodge, T. P. \& Fauron, C. M. 1984 The physical map and organization of the mitochondrial genome from the fertile cytoplasm of maize. Nucleic Acids Res. 12, 9249-9261.

Martin, W., Stoebe, B., Goremykin, V., Hansmann, S., Hasegawa, M. \& Kowallik, K. V. 1998 Gene transfer to the nucleus and the evolution of chloroplasts. Nature 393, $162-165$

Morse, D., Salois, P., Markovic, P. \& Woodland Hastings, J. 1995 A nuclear-encoded form II RuBisCo in dinoflagellates. Science 268, 1622-1624.

Nakamura, Y., Kaneko, T., Hirosawa, M., Miyajima, N. \& Tabata, S. 1998 Cyanobase, a www database containing the complete nucleotide sequence of the genome of Synechocystis sp. strain PCC6803. Nucleic Acids Res. 26, 63-67.

Palmer, J. D. 1993 A genetic rainbow of plastids. Nature 364, 762-763.

Pfannschmidt, T., Nilsson, A. \& Allen, J. F. 1999 Photosynthetic control of chloroplast gene expression. Nature 397, $625-628$ 
Race, H. L., Herrmann, R. G. \& Martin, W. 1999 Why have organelles retained genomes? Trends Genet. 15, 364-370.

Recchia, G. D. \& Hall, R. M. 1997 Origins of the mobile gene cassettes found in integrons. Trends Microbiol. 5, 389-394.

Reith, M. \& Munholland, J. 1995 Complete nucleotide sequence of the Porphyra purpurea chloroplast genome. Plant Mol. Biol. Rep. 13, 333-335.

Rowe-Magnus, D. A. \& Mazel, D. 1999 Resistance gene capture. Curr. Opin. Microbiol. 2, 483-488.

Rowe-Magnus, D. A. \& Mazel, D. 2001 Integrons: natural tools for bacterial genome evolution. Curr. Opin. Microbiol. 4, 565-569.

Stern, D. B., Radwanski, E. R. \& Kindle, K. 1991 A 3' stem/loop structure of the Chlamydomonas chloroplast atp $B$ gene reguates mRNA accumulation in vivo. Plant Cell 3, 285-297.

Sugiura, M. 1992 The chloroplast genome. Plant Mol. Biol. 19, 149-168.

Zhang, Z., Green, B. R. \& Cavalier-Smith, T. 1999 Single gene circles in dinoflagellate chloroplast genomes. Nature 400, 155-159.

Zhang, Z., Green, B. R. \& Cavalier-Smith, T. 2000 Phylogeny of ultra-rapidly evolving dinoflagellate chloroplast genes: a possible common origin for sporozoan and dinoflagellate plastids. F. Mol. Evol. 51, 26-40.

Zhang, Z., Cavalier-Smith, T. \& Green, B. R. 2001 A family of selfish minicircular chromosomes with jumbled chloroplast genes from a dinoflagellate. Mol. Biol. Evol. 18, 1558-1565.

Zhang, Z., Cavalier-Smith, T. \& Green, B. R. 2002 Evolution of dinoflagellate unigenic minicircles and the partially concerted divergence of their putative replicon origins. Mol. Biol. Evol. 19, 489-500.

\section{Discussion}

R. Fray (Plant Science Division, University of Nottingham, Nottingham, UK). Have you looked at the transcripts from these minicircles? Do you get a defined-length transcript or does the RNA polymerase just keep going round these circles many times?

C. J. Howe. That is a good question. We do find defined-length transcripts, and they correspond essentially with the size that one would expect from the coding region itself, with a little bit added on at each end. They do not correspond to the size of the whole minicircle, and in the cases where we have two genes in the minicircle we seem to find separate transcripts for each gene. Now that does not rule out the possibility of a much larger transcript that is processed very rapidly, so we do not pick up the intermediate dicistronic transcript, but we seem to find just single-sized transcripts.

C. J. Leaver (Department of Plant Sciences, University of Oxford, Oxford, UK). Does the copy number of these circles or those genes vary relative to each other, or when you culture these, or is it constant?

C. J. Howe. We have looked at that to some extent. It is curious that one of the genes that you seem to pick up quite often when you are cloning these minicircles is the $p s b A$ minicircle. We thought everything needs lots of $p s b A$ because it is turning over very rapidly, so maybe the dinoflagellates have many copies of the $p s b A$ compared with the other genes, so they make lots and lots of protein. But like all the best hypotheses, that turned out to be wrong. Copy number experiments that we have done suggest that the minicircles all seem to occur in fairly similar numbers of copies. There is not a specific overrepresentation of the $p s b A$, although we have not yet looked at variation in copy numbers during culturing, during life cycle and so on.

J. E. Walker (MRC-Dunn Institute of Human Nutrition, Cambridge, $U K)$. There is a related question to your initial question 'why should genes move from the chloroplast to the nucleus?', and that is: why should genes stay in the chloroplast? Do you know? I cannot comment on chloroplasts, but certainly in the case of mitochondria of higher organisms, the 13 proteins that are encoded there have one very clear, common feature: they are very hydrophobic, and therefore it is reasonable to assume that they have been kept there because they would be difficult to transport into the mitochondrion; they would probably need to be kept soluble during that process and this would require the addition of an enormously long polar import sequence. One is encouraged that that may be so by subunit c, which is about 80 amino acids long; it is a nuclear gene product and it has an import sequence, if I remember correctly, in excess of 60 extremely polar amino acids, so certainly in the case of these mitochondria and their genomes that may be one of the overriding factors.

C. J. Howe. In the chloroplast system it has certainly been shown in a number of cases that one can take a chloroplast gene and put it into the nucleus with a chloroplast import sequence that has nothing particularly special attached to it and that import sequences will take the gene product back into the chloroplast. So some genes could, at least in principle, be moved into the nucleus.

J. E. Walker. Similar experiments have been done by Howard Jacobs with the ATPase 6 gene, which has been moved into the nucleus, and he has had to attach an extremely long polar import sequence in order to achieve that.

C. J. Howe. John Allen has, of course, theories on the retention of genes. I have a theory on the retention of one gene, which is the glutamate tRNA that is used to activate glutamate for haem biosynthesis. If you are not really able to import tRNAs into the organelle, but at least the early stages of haem biosynthesis are carried out in the organelle, then you will at least have to retain that glutamate tRNA gene. Obviously, that leaves a lot of others to be explained.

J. C. Gray (Department of Plant Sciences, University of Cambridge, Cambridge, UK). Integrons have a relatively short recognition sequence, and not the 500 base pairs that you have as your common region. Surely that would suggest your common region is doing something else rather than providing an integration-recognition site?

C. J. Howe. Yes, it may well be doing something else. In classic integrons, they talk about a $59 \mathrm{bp}$ element (which in fact can be anything from 59 to about $150 \mathrm{bp}$ ). Within the minicircle core region there are regions of greater conservation and lesser conservation, so it is possible that one part of the core might be functioning as that kind of attachment site while the rest could be doing other things, such as acting as a promotor or indeed supplying a replication origin, allowing the whole thing to replicate independently - this is just speculation. There are quite a lot of short inverted repeats in these core regions, which is interesting because one of the features of the $59 \mathrm{bp}$ elements in the integron model is that they also have inverted repeats bounding them, so there is an extension of that similarity. 
A. E. Douglas (Department of Biology, University of York, York, UK). I have a speculative comment/question. Dinoflagellate plastids have been replaced by alternative photosynthetic symbionts in some taxa. I wonder if this could be related to the fact that their genome may be degenerate or prone to collapse. Do you want to make any comment?

C. J. Howe. Only that that it is a very interesting observation. I do not know. I would emphasize that dinoflagellates are an incredibly broad group of organisms, and the people looking at them have just picked out a small number. I think we need to look more broadly within the group and see what we can find.

T. Cavalier-Smith (Department of Zoology, University of Oxford, Oxford, UK). Can I comment on the last question? The fundamental reason why dinoflagellates can relatively easily undergo chloroplast replacement, which has happened at least twice, maybe three times, is that they are the only group of chromalveolates that has retained the membrane vesicle targeting mechanism and photosynthesis, and the ability to phagocytose. All the chromists underwent that fusion of the endoplasmic reticulum with the epiplastid membrane. Therefore, if a chromist ate a foreign alga and failed to digest it, it would not already have a vesicle targeting mechanism that could be used to enslave the new plastid; whereas dinoflagellates have it ready-made, they just have to slightly alter the v-SNARE so that they can re-target it to the new food vacuole membrane. It would be relatively easy. That, I think, is the reason.

C. J. Howe. It sounds extremely plausible to me, yes.

J. F. Allen (Plant Biochemistry, Lund University, Lund, Sweden). Concerning hydrophobicity, in response to John Walker, I intended to send the hydrophobicity hypothesis packing yesterday. This is something that one should discuss, but it does not really come in the context of Chris Howe's talk.
R. G. Herrmann (Department of Biology, LudwigMaximilians Universität, Munich, Germany). I can make a comment on the import of highly hydrophobic proteins. We have imported a protein with 11-transmembranespanning protein segments into the chloroplast. The problem does not appear to be one of import, but of interaction with the chaperones, so the proteins are sometimes not correctly inserted in the membrane. If one can modify the chaperone/hydrophobicity protein in its action, it should be possible to have chloroplast function of such a hydrophobic protein encoded by the nucleus.

J. F. Allen. I think that John Walker's point was that hydrophobicity may not be an obstacle to import in plastids, but it could be in mitochondria.

R. E. Blankenship (Department of Chemistry and Biochemistry, Arizona State University, AZ, USA). Is there evidence against full-sized chloroplast genomes in these organisms? In other words, are you sure there is no larger structure?

C. J. Howe. That is clearly an extremely important question. We have tried very hard to find one. We have tried, for example, 'PCRing' with primer pairs for genes that would be adjacent on any respectable large chloroplast DNA to see if we can obtain PCR products with them both on, but we cannot. Clearly there could be other trivial reasons for that, so it needs to be looked at.

\section{GLOSSARY}
A: adenine
C: cytosine
$\mathrm{G}$ : guanine
RT-PCR: reverse transcription-polymerase chain reaction $\mathrm{T}$ : thymine 